\title{
Correction to: Impact of climate change on landslides frequency: the Esino river basin case study (Central Italy)
}

\section{Lorenzo Sangelantoni $^{1,2}$ (D) Eleonora Gioia $^{2} \cdot$ Fausto Marincioni $^{2}$}

(C) Springer Science+Business Media B.V., part of Springer Nature 2018

\section{Correction to: Nat Hazards https://doi.org/10.1007/s11069-018-3328-6}

In equation (2) the term " $\mathrm{P}\left(\mathrm{L} \vee \mathrm{R}, \mathrm{A}_{5}\right)$ " should be replaced with " $\mathrm{P}(\mathrm{L} / \mathrm{R}, \mathrm{A} 5)$ " and the term "P(R, $\left.A_{5}\right) \vee L "$ should be replaced with "P(R, $\left.A_{5} I L\right)$ ". A typographical error replaced the symbol "l" with the symbol " $\vee$ ".

The corrected equation (2) appears below:

$$
P\left(L \mid R, A_{5}\right)=\frac{P\left(R, A_{5} \mid L\right) \cdot P(L)}{P\left(R, A_{5}\right)}
$$

This formula was coded correctly in our analysis, and the errors in reporting the equation do not affect any of the results reported in the paper.

The original article can be found online at https://doi.org/10.1007/s11069-018-3328-6.

Lorenzo Sangelantoni

1.sangelantoni@univpm.it

1 Department of Physical and Chemical Sciences, CETEMPS, Università dell'Aquila, 67100 L'Aquila, Italy

2 Department of Life and Environmental Sciences, Università Politecnica delle Marche, 60131 Ancona, Italy 